\title{
Baudelaire en vers català: «Don Juan aux Enfers»
}

\author{
Joaquim Sala-Sanahuja \\ Universitat Autònoma de Barcelona. Facultat de Traducció i d'Interpretació \\ Edifici K \\ 08193 Bellaterra \\ joaquim.sala@uab.cat \\ ORCID: 0000-0002-1548-0129
}

\section{Resum}

A partir del poema «Don Juan aux enfers», de caràcter narratiu, inclòs a Les Fleurs du Mal, de Charles Baudelaire, el text presenta una anàlisi de les qüestions traductives lligades al mite de Don Juan i als mitologemes que en deriven. El corpus de referència són tres versions catalanes, totes prosòdiques. La finalitat és, doncs, de trobar un mètode ràpid i eficaç d'anàlisi estilística comparada, prèvia en tot cas a la recerca crítica més fina. Alhora s'ofereix informació sobre els autors de les tres versions comparades: Emili Guanyabéns (1860-1941), Rossend Llates (1899-1973) i Xavier Benguerel (1905-1990), amb observacions sobre l'estil traductiu de cadascun.

Paraules clau: traducció; Baudelaire; estilística; prosòdia; comparatisme

\section{Abstract. Baudelaire in Catalan verse: "Don Juan aux Enfers"}

Based on the narrative poem "Don Juan aux enfers", in Les Fleurs du Mal by Charles Baudelaire, the text analyzes the translation issues linked to the myth of Don Juan and the mytholemes that stem from it. The reference corpus consists of three Catalan prosodic versions. The goal is therefore to find a rapid and efficient method of comparative stylistic analysis, in any case prior to more detailed critical research. At the same time, information is provided on the authors of the three compared versions: Emili Guanyabéns (1860-1941), Rossend Llates (1899-1973) and Xavier Benguerel (1905-1990), with observations on the translation style of each of them.

Keywords: translation; Baudelaire; stylistics; prosody; comparativism

\section{Sumari}

1. Els traductors Referències bibliogràfiques

2. El títol i el poema Annex 
L'any 1998, arran del III Congrés de Traducció, vaig presentar una ponència sobre diverses traduccions catalanes d'un poema de Charles Baudelaire, «Don Juan aux enfers», inclòs a Les Fleurs du Mal. Me'n va quedar la recança d'haver tractat la qüestió del mite i del mitologema en la traducció, però sense observar els textos en el detall. Ara m'agradaria rescabalar-me'n, i per això intentaré confrontar breument tres d'aquestes versions catalanes acarades a l'original. La finalitat és, doncs, de trobar un mètode ràpid i visualitzable — per no dir visible — d'anàlisi comparada. Eventualment ens referirem a alguna versió anglesa de les tantes i tantes que d'aquest poema es poden trobar. Prenem, doncs, «Don Juan aux Enfers» de Charles Baudelaire, un dels poemes de Les Fleurs du Mal, com a punt de partença, per acarar-lo a tres versions de tres traductors coneguts: Emili Guanyabéns, Rossend Llates i Xavier Benguerel.

\section{Els traductors}

Emili Guanyabéns —o també, de vegades, Guanyavents, amb una transcripció més poètica - va publicar la primera versió d'aquest poema l'any 1898 a la revista Catalònia (número 1, p. 12 i 13) i després la va incloure al volum Trasplantades, un recull important de la poesia francesa del segle XIX en versions catalanes prosòdiques, publicades a la «Biblioteca Popular de L'Avenç» l'any 1910. És l'únic poema de Baudelaire que va «trasplantar» aquest magnífic traductor, que va haver de patir les crítiques minucioses del prologuista mateix, el poeta francocatalà Joan Pérez-Jorba, el qual, al cap de poc temps, havia de publicar moltes versions d'Apollinaire, Reverdy, Pierre Albert-Birot, Tristan Tzara o Max Jacob. És Perez-Jorba, segurament, que va presentar Pierre Reverdy a Joaquim Folguera i a Josep Maria López-Picó, que el van nomenar corresponsal a París de La Revista quan encara no havia publicat res en francès. En referència també a Pérez-Jorba, haig de dir — perquè si no ho dic ara, ja no ho diré mai més- que, arran del robatori a París d'un quadre de Gustave Moreau en possessió d'un amic, vaig conèixer en una època un fill seu, Jacques Pérez-Jorba, comissari de policia al 26, quai des Orfèvres, especialitzat en la repressió de robatoris i tràfic d'obres d'art, i també autor de novelles policíaques amb el pseudònim de Julien Clay. Que nosaltres sapiguem, Trasplantades és l'únic volum de traduccions que va publicar Guanyabéns. Es tracta d'un recull de les versions de poesia que havia anat publicant de manera dispersa i que és per a nosaltres, avui encara, una obra de referència en l'àmbit de la traducció poètica.

Rossend Llates va publicar la seva versió del poema «Don Juan aux enfers» en un recull de poemes, uns setze, de Les Fleurs du Mal, luxosament editat per la Llibreria Catalònia l'any 1926. El llibre, en edició numerada, amb illustracions de Xavier Güell a la manera d'Aubrey Beardsley, era destinat més aviat als «bibliòfils», i per això va ser poc divulgat als aparadors i a les revistes; més aviat es venia a les rerebotigues dels llibreters, entenem que per una qüestió de decència. Ja s'intueix que aquests poemes, l'any 1926, tenien el mateix efecte en el públic català que el que havia tingut l'original en els lectors francesos l'any 1857, data de la primera edició, que aviat va ser segrestada per les autoritats. De Ros- 
send Llates en sabem quatre detalls que explicaran sens dubte moltes de les opcions de la seva traducció. Crític musical i compositor, va crear juntament amb la seva muller, la pianista Maria Canals, l'Acadèmia Ars Nova, un centre de formació musical, l'any 1950. En aquest punt, faré una digressió: el pare Hilari Raguer, que ens va deixar pocs dies abans que aquestes Jornades comencessin, havia aportat temps enrere diverses informacions de primera mà sobre Llates que nosaltres ens atrevim a completar a partir de la correspondència coneguda del novel-lista Louis Ferdinand Céline durant la seva etapa d'exili a Dinamarca, després de sortir de la presó en aquell país. ${ }^{1}$ Per a la petita història, doncs, direm que Rossend Llates i Serrat era nebot de Francesc Serrat i Bonastre, que va ser secretari de Relacions Exteriors de la Junta Técnica del Estado, a Salamanca, el primer govern del general Franco, és a dir, un «protoministre» d'afers estrangers del dictador. En unes memòries íntimes del començament dels anys cinquanta, poc abans de morir, adreçades als seus fills — i no pas destinades a la publicacióSerrat va deixar una descripció molt cruel de Franco i dels oportunistes que es movien per Burgos durant la guerra civil. ${ }^{2}$ Hi parla entre moltes altres coses de les cuites del seu nebot, Rossend Llates, que intentava veure'l en entrar des d'Irun, el 1937, tot i els advertiments de Serrat perquè es quedés a França, i que no anés a Burgos, on el podien detenir — com efectivament va passar. D'altra banda, un fill del diplomàtic, i, doncs, cosí de Llates, Juan Serrat i Valera, successivament cònsol a Budapest i a Varsòvia, apareix diverses vegades a la correspondència de Louis Ferdinand Céline, com també Antonio Zuloaga, fill del cèlebre pintor i aleshores agregat cultural de l'ambaixada espanyola a París. ${ }^{3}$ El fet és novellesc i mereixeria una descripció més detallada: Céline havia dipositat una certa quantitat d'or, producte dels seus drets d'autor a l'estranger, a les mans d'una examant seva, la ballarina Karen Marie Jensen, la qual va enterrar el tresor al jardí de casa seva, a Copenhaguen, una casa on Celine i la seva muller Lucette van viure els primers temps de l'exili a Dinamarca. La ballarina, per aquells anys, vivia a Madrid, amistançada, com se sol dir, amb Serrat Valera. Durant un temps, segons les cartes, Céline va tenir l'esperança d'obtenir, gràcies a Serrat, un passaport per installar-se a Barcelona, on Lucette Almansor, la seva muller, podria fer classes de ballet. Segurament a l'acadèmia Ars Nova, del cosí Rossend Llates, diem ara nosaltres. Finalment, Céline va poder tornar a França l'any 1951, i la hipòtesi barcelonina va quedar en no res. Cal afegir que al començament dels anys cinquanta Barcelona - i Catalunya en general - encara era un niu d'emboscats de la Colllaboració. Les versions baudelairianes de Llates són de la seva època de joventut, com també el Resum de mètrica catalana, escrit juntament

1. CÉLINE, Louis-Ferdinand. Lettres. París: Gallimard, «Collection La Pléiade», 2009, pàssim.

2. Serrat Bonastre, Francisco. Salamanca, 1936. Memorias del primer «ministro» de Asuntos Exteriores de Franco. Edició i Estudi d’Ángel Viñas. Crítica. Ed. Planeta, 2014.

3. Zuloaga havia treballat, el 1937, a l'Oficina d'Informació Espanyola que Cambó havia creat a París per fer propaganda a favor del bàndol nacional. També hi treballaven Joan Estelrich, Joan Llonch, Octavi Saltor, Francesc Tomàs, etc. Vegeu Martin Berbois, J. L., Epistolari entre Miquel Carreras i Costajussà i Joan Llonch i Salas (1936-1938). Barcelona: Editorial Mediterrània, 2007. 
amb Alfons Serra i Baldó («Col·lecció Popular Barcino», 1932), que molts de nosaltres consultàvem quan ens vam llançar als atzars de la literatura.

I finalment, Xavier Benguerel, segurament el traductor més divulgat de tots tres, tant per les seves traduccions dels pinyols de la literatura en vers (Poe, Valéry, Baudelaire, Lafontaine) com per la seva activitat de novel-lista, que va menar paral-lelament a la feina d'empresari farmacèutic. En el cas de la traducció em poso jo mateix com a testimoni, atès que el vaig tractar durant els anys vuitanta i gairebé fins a la seva mort, el 1990, en qüestions directament relacionades amb les seves versions de poesia francesa: el Narcís de Paul Valéry, Les Flors del Mal, de Charles Baudelaire, i Les Faules, de Lafontaine. La tècnica de Benguerel, com veurem, sol ser més complexa que la dels altres dos traductors, en el sentit que intervé en l'estructura del text per tal de preservar-ne la prosòdia i evitar les pèrdues semàntiques, una de les seves grans preocupacions. Amb dues figures de traducció molt reiterades i característiques del seu estil: l'hipèrbaton i la compensació. L'edició que analitzarem d'aquest poema és del 1985, en la versió de Les flors del mal de les Edicions del Mall.

Més enllà d'aquestes tres edicions de Les flors del mal, cal esmentar, tot i que no s'estudiaran aquí, les de Josep Capdevila i Rovira a les «Publicacions de La Revista» (1920), de Joan Peña (1985), totes dues parcials, i les més recents, de Jordi Llobet, a Edicions 62 (2007).

\section{El títol i el poema}

\begin{tabular}{llll}
\hline Charles Baudelaire & Xavier Benguerel & Emili Guanyabéns & Rossend Llates \\
\hline Don Juan aux enfers & Don Joan als inferns & Don Juan a l'infern & Don Joan a l'infern
\end{tabular}

a) El mitologema «Don Juan», d'arrel espanyola, sevillana, es manté en l'original i en la traducció de Guanyabéns (que compta «Juan» amb diftong, a la castellana). Benguerel i Llates, en canvi, el semicatalanitzen: «Don Joan».

b) «Les enfers» designa els inferns pagans, l'Hades, o el món dels morts. És un lloc de repòs, i no pas de càstig, com ho seria l'infern cristià (en singular). En morir, les ànimes dels difunts anaven a la regió que els pertocava en funció de la seva vida terrenal. Virgili en fa una descripció detallada (Llibre VI de l'Eneida). Moltes de les traduccions angleses tradueixen «les enfers» per «Hades». El singular de Guanyabéns i de Llates estableix, doncs, un rerefons cristià que no explicaria gens l'actitud indiferent, cínica, de Don Joan dalt la barca de Caront, abandonant al seu darrere les seves amants errants, convertides en vaques que mugeixen darrere seu, a l'altra riba.

c) El tema: poema narratiu limitat a la sequiència de la davallada de Don Juan als inferns, extret del quart acte del Don Juan de Molière. El destí del Don Juan de Molière difereix notòriament dels «Don Juan» romàntics, perquè en el poema de Baudelaire no hi ha càstig — i si n'hi ha, és per a les amants seduïdes que no poden travessar la ribera Estígia i arribar a l'Hades. Don Juan manté la seva amoralitat fins al final («... et ne daignait rien voir»). 
d) Estructura mètrica: cinc quartets d'alexandrins francesos, de dos hemistiquis simètrics cadascun, amb la rima alternada i amb alternança, també, de mots aguts i plans al final de cada vers. Totes tres versions mantenen idènticament aquesta estructura mètrica. Només Guanyabéns pren alguna llicència en la diftongació: «Don Juan» compta per dues sílllabes, com en castellà.

Tot seguit comparem les tres versions segons els diversos paradigmes que apareixen en la seqüència de la narració: la mort en primer lloc, amb les figures metonímiques de l'aigua i de la foscor, i després la reconstitució dels petits mites i submites (Stix, Caront i Antístenes).

\section{A) Paradigma de la mort}

1. L'aigua: figura simbòlica de la mort

\begin{tabular}{llll}
\hline $\begin{array}{l}\text { Versió 1: Baudelaire } \\
\text { Versió 2: X. } \\
\text { Benguerel }\end{array}$ & $\begin{array}{l}\text { Versió 3: } \\
\text { Guanyabéns } \\
\text { ona tenebrosa (v. 1) } \\
\text { (v. 1) }\end{array}$ & ona soterrada (v. 1) \\
\hline & $\begin{array}{l}\text { pel pas del riu (v. 2) } \\
\text { les rivages (v. 11) }\end{array}$ & $\begin{array}{l}\text { les riberes vagues } \\
\text { (v. 11) }\end{array}$ & \\
\hline flot noir (v. 18) & flux espès (v. 18) & fosc corrent (v. 18) \\
\hline le sillage (v. 19) & $\begin{array}{l}\text { els solcs de l'aigua } \\
\text { (v. 19) }\end{array}$ & l'estel' \\
\hline 4 ocurrències & 4 ocurrències & 1 ocurrència & 3 ocurrències \\
\hline
\end{tabular}

El sema «aigua», sinècdoque del mític riu Stix, que implanta la idea de la mort pagana i alhora el submite de Caront, es manté perfectament en la versió de Benguerel, sobretot amb la compensació del segon vers («pel pas del riu»); gairebé desapareix en la de Guanyabéns, reduïda a la traducció literal del primer vers; i minva relativament en la versió de Llates, en què desapareix la noció de «ribera» (i, doncs, del pas explícit al món dels inferns).

2. Paradigma de la foscor

\begin{tabular}{|c|c|c|c|}
\hline Versió 1: Baudelaire & $\begin{array}{l}\text { Versió 2: X. } \\
\text { Benguerel }\end{array}$ & $\begin{array}{l}\text { Versió 3: } \\
\text { Guanyabéns }\end{array}$ & Versió 4: R. Llates \\
\hline $\begin{array}{l}\text { onde souterraine } \\
\text { (v. 1) }\end{array}$ & $\begin{array}{l}\text { avencs ombrosos } \\
\text { (v. 1) }\end{array}$ & ona tenebrosa (v. 1) & ona soterrada (v. 1) \\
\hline $\begin{array}{l}\text { sombre mendiant } \\
\text { (v. } 3 \text { ) }\end{array}$ & & $\begin{array}{l}\text { mendicant obscur } \\
\text { (v. } 3 \text { ) }\end{array}$ & \\
\hline \multirow[t]{2}{*}{$\begin{array}{l}\text { noir firmament } \\
\text { (v. 6) }\end{array}$} & cel ennegrit (v. 6) & negre cel (v. 8) & fosc firmament (v. 6) \\
\hline & $\begin{array}{l}\text { riberes vagues } \\
\text { (v. 11) }\end{array}$ & & \\
\hline
\end{tabular}


mugien foscament

(v. 8)

\begin{tabular}{llll}
\hline front blanc (v. 12) & front gris (v. 12) & blanc front (v. 12) & front blanc (v. 12) \\
\hline deuil (v. 13) & dol (v. 13) & dol (v. 13) & dol (v. 13) \\
\hline $\begin{array}{l}\text { où brillât la douceur } \\
\text { (v. 16) }\end{array}$ & $\begin{array}{l}\text { on brillés la dolcesa } \\
\text { (v. 16) }\end{array}$ & una guspira (v. 15) & $\begin{array}{l}\text { on brillés la dolçor } \\
\text { (v. 16) }\end{array}$ \\
\hline flot noir (v. 18) & & & fosc corrent (v. 18) \\
\hline Total: 7 ocurrències & Total: 6 ocurrències & Total: 7 ocurrències & Total: 6 ocurrències \\
\hline
\end{tabular}

Aquest paradigma, que destaca en l'original de Baudelaire pel contrast directe $i$ fort entre el blanc (1 ocurrència) i el negre ( 2 ocurrències, fet inusual en un poema clàssic, llevat de casos d'anadiplosi), minva en les tres versions catalanes: Benguerel només hi inclou el «gris», que respecta la metonímia, però atenua el contrast; Guanyabéns el respecta en dos casos: «negre cel» i «blanc front»; i Llates el manté tan sols a «front blanc». En certa manera, aquesta minva del contrast atenua l'efecte fort de la foscor de la versió original. La penúltima estrofa conté una metonímia important, amb canvi d'isotopia: «un suprême sourire / où brillât la douceur /de son premier serment». Perquè enmig de l'abstracció «douceur» destaca la «brillantor» del «somriure suprem», és a dir, de les dents. Tots tres traductors conserven el verb «brillar», llevat de Guanyabéns, que el compensa amb «guspira» al vers precedent. Cal destacar encara la compensació de Benguerel: «riberes vagues» per «sombre mendiant»; i també la de Guanyabéns, «mugien foscament» per «long mugissement», que reforça la tonalitat fúnebre de «negre cel» al mateix vers. En resum, el sentit directe i fort de «foscor» en Baudelaire es va atenuant una mica en totes les traduccions, sobretot perquè imposen també una percepció més metafòrica del paradigma.

\section{B) Mite i mitologemes}

El mite de Caront, com la majoria dels mites clàssics, va ser una forma estereotipada fins ben entrat el segle xx. Com per a tota la mitologia grega, aquestes formes es van fins i tot lexicalitzar de vegades amb l'ensenyament de l'estil a partir d'obres com ara Les Aventures de Télémaque, de Fénélon (1699), un compendi novel-lat de tots els mites clàssics. Com a llibre preceptiu de lectura, l'obra de Fénélon s'integra en l'ensenyament regular de la retòrica a França i a la majoria de països europeus; també a Catalunya, amb l'arribada dels jesuïtes i del seu mètode d'ensenyament, i després amb la dels ordes religiosos ensenyants expulsats de França. Corrent, doncs, fins a gairebé els anys trenta del segle xx a Catalunya, el coneixement dels mites va passar d'ençà d'aleshores a l'àmbit de l'erudició. Aquest fet explica la necessitat d'explicitar, en les traduccions més recents, alguns dels elements narratius del mite o bé, simplement, de suprimir-los. És el sentit, per exemple, de l'amplificació de Benguerel «pel pas del riu», al vers 2 , una crossa que ell incorpora a la seva versió per dues raons: compensar la pèrdua de l'«aigua» del primer vers, i explicitar, en segon lloc, el mite de Caront. 
L'original de Baudelaire, d'altra banda, incorpora una referència al mite d'Antístenes, o Antisthène, no tan conegut, sens dubte, com el de Caront. En la primera estrofa es tracta visiblement d'una aparició incidental, en forma de comparació, i per aguantar la rima amb «souterraine». Si per al lector del segle XIX aquesta comparació devia ser clara, en el sentit de convertir Caront en un personatge altiu, per al lector del final del xx la comparació ja és hermètica. Benguerel, sempre preocupat per evitar la pèrdua, manté el mitologema, però ho fa un vers més enllà, i encara simplificant la sinècdoque de l'original («l'œil fier comme Antisthène») per convertir-la en «a imatge d'Antístenes l'altiu». Els altres dos traductors eliminen la comparació, un fet que comporta, és clar, la desaparició d'Antístenes.

Un gest traductiu important en la traducció de Rossend Llates, i que no volem passar per alt, és la utilització de dos mots d'arrel gòtica a la darrera estrofa: «bran» $\mathrm{i}$ «osberg». Llates, crític musical, com hem vist, i gran wagnerià, aprofita l'ocasió per convertir «l'armure» (l'armadura) del personatge en un «ausberg» (osberg), i «la rapière» (el pom de l'estoc) en un «bran». Aquesta tendència germanitzant venia del lèxic que Jeroni Zanné, Joaquim Pena i Antoni Ribera/Josep Lleonart havien implantat en traduir al català els llibrets de les òperes de Wagner. Una marca «gòtica» que s'adiu ben poc amb els tòpics llatins que el mite del Don Juan arrossega des de fa segles. Estrany contrast, doncs, que imposa una certa confusió en la denotació estricta del vers: confusió d'un univers germànic sense gaires sentiments morals (Siegfried pot occir per l'esquena, per exemple, sense més recança ni penediment ni deshonor) i un univers llatí donjuanesc, amarat de prejudicis, però sovint amb un tombant pervers.

Uns aclariments, abans d'acabar, sobre la tècnica traductiva de Xavier Benguerel, tan comentada per ell mateix i per d'altres. Ja hem avançat que en les seves versions de poesia apareix, de rerefons, una obsessió de la pèrdua, tant lèxica com retòrica. En veiem un exemple en el poema «Cant tardoral», versió de «Chant d'Automne», també de Les Fleurs du mal. En aquest poema Baudelaire veu als ulls de la seva amant — la femme-fatale — una «lumière verdâtre» a final de vers, que més avall farà rimar amb el cultisme francès «âtre» (llar). La traducció de Benguerel ho resol amb dues figures; en primer lloc la «lumière verdâtre» és traduïda amb una amplificació curiosa i audaç: «un to mig verd mig d'ambre», que farà rimar amb «cambra» (per «boudoir»); i en segon lloc «âtre» és traduït per «llar», lògicament, perquè un cultisme seria improbable i eventualment malentès; però recuperarà el cultisme més avall, en traduir «automne» per «autumne», de manera que hi hagi compensació retòrica. En l'ordre de la prosòdia, igualment, Benguerel parava molta atenció al ritme: afirmava que el ritme de caminar - perquè feina una llarga caminada cada dia - li proporcionava el ritme del vers, que recordava de memòria, i així modulava els mots i els apuntava en una llibreta que duia sempre al damunt. En tot cas, l'estil traductiu de Benguerel es distingeix visiblement de tots els altres pel fet que intenta evitar quasi obsessivament la pèrdua, tant lèxica com retòrica.

L'ordre en l'execució de Benguerel de la traducció d'un poema era el següent: per reconstituir la «gàbia», és a dir, els mots finals de cada vers original, a) provar la traducció literal de les rimes (d'aquesta manera en podia conservar poc o 
molt un bon grapat); $b$ ) buscar en els «ocells» (els mots de l'interior del vers) una possible rima que aleshores aconsegueix, si n'hi ha, fent-hi un hipèrbaton; c) intercanviar les categories sintàctiques, eventualment amb una abstracció, $\mathrm{i}$ així successivament; $d$ ) introduir, si cal, llicències en alguns mots («pro» per «però», etc.); $f$ ) finalment, el català, més abundant de mots aguts, i amb molts monosíllabs, li deixava marge per amplificar: el mitologema, doncs, li servia amb safata l'explicitació del tema.

Val a dir que aquest estil és, en Benguerel, universal: l'aplicava a tots els poetes que traduïa; però em sembla més adient en les traduccions de Paul Valéry que en Baudelaire o Poe - tot i que en aquest darrer l'arquitectura sonora camufla un bon nombre d'hipèrbatons. De retruc les seves versions de Baudelaire tenen un so més dens, un poc abarrocat, que de vegades pot desservir el poema. Era el seu estil.

\section{Referències bibliogràfiques}

Baudelaire, Charles (1985). Les flors del Mal. Traducció de Xavier Benguerel. Barcelona: Edicions del Mall.

- (1926). Les Flors del Mal. Traducció de Rossend Llates. Barcelona: Llibreria Catalònia. CÉLINE, Louis-Ferdinand (2009). Lettres. París: Gallimard (Collection La Pléiade).

Guanyabéns, Emili (1910). Trasplantades. Barcelona: L’Avenç.

Martin Berbois, Josep Lluís (2007). Epistolari entre Miquel Carreras $i$ Costajussà $i$ Joan Llonch i Salas (1936-1938). Barcelona: Mediterrània.

Serrat Bonastre, Francisco (2014). Salamanca, 1936. Memorias del primer «ministro» de Asuntos Exteriores de Franco. Edició i estudi d'Ángel Viñas. Barcelona: Crítica; Planeta.

\section{Annex}

Baudelaire, Charles (1857). «Don Juan aux enfers». A Les Fleurs du Mal. Edició de Poulet-Malassis i De Broisse. París.

\section{DON JUAN AUX ENFERS}

Quand Don Juan descendit vers l'onde souterraine Et lorsqu'il eut donné son obole à Charon, Un sombre mendiant, l'œil fier comme Antisthène, D'un bras vengeur et fort saisit chaque aviron.

Montrant leurs seins pendants et leurs robes ouvertes, Des femmes se tordaient sous le noir firmament, $\mathrm{Et}$, comme un grand troupeau de victimes offertes, Derrière lui traînaient un long mugissement.

Sganarelle en riant lui réclamait ses gages, Tandis que Don Luis avec un doigt tremblant Montrait à tous les morts errant sur les rivages Le fis audacieux qui railla son front blanc. 
Frissonnant sous son deuil, la chaste et maigre Elvire,

Près de l'époux perfide et qui fut son amant,

Semblait lui réclamer un suprême sourire

Où brillât la douceur de son premier serment,

Tout droit dans son armure, un grand homme de Pierre

Se tenait à la barre et coupait le flot noir;

Mais le calme héros, courbé sur sa rapière,

Regardait le sillage et ne daignait rien voir.

Traducció d'Emili Guanyabéns, 1910

\section{DON JUAN A L'INFERN}

Quan va baixar don Juan vers l'ona tenebrosa, tantost hagué donat son obol a Caró,

un mendicant obscur, d'ullada esgarrifosa, va prendre-1s rems amb braç ferreny i venjadô.

Mostrant llurs pits caiguts, llurs robes entreobertes, de dones un sens fi, llurs cossos retorcent, seguint com un ramat de victimes ofertes per sota.l negre cel, mugien foscament.

Sganarelle, rient, sos guanys li reclamava, alhora que don Luis, tot tremolant-li.l dit, a tots els morts errants per aquells volts, mostrava lo fill qui son blanc front va profanâ atrevit.

Trement sota 1 seu dol, la casta i magra Elvira, aprop dels fals espòs qui son amant va ser, semblava reclamar tant sols una guspira del saborós somrís del jurament primer.

Un homenaç de pedra, dret dintre sa armadura, la mà en el governall, guiava·l tètric bot. Mes l'heroe, com distret, en indolent postura, tranquil mirava 1 solc, despreciant-ho tot. 
Traducció de Rossend Llates, 1926

\section{DON JOAN A L'INFERN}

Quan don Joan baixà vers l'ona soterrada i hagué dat a Caron el seu òbol suprem, un captaire sorrut d'orgullosa mirada, amb braç fort, venjatiu, va prendre cada rem.

Mostrant llur pit penjant i les robes obertes, es retorçaven dones sota el fosc firmament, i com un gran ramat de víctimes ofertes darrera arrossegaven un llarg braolament.

Rialler Sganarel li reclamava els gatges, mentre que don Lluís amb un dit tremolós mostrava a tots els morts errants per'quells paratges el fill que son front blanc burlava, audaciós.

La casta i magra Elvira sota el dol aclofada, a prop del marit pèrfid i que fou son amant semblava reclamar-li l'última llambregada on brillés la dolçor d'aquell primer instant.

Un gran home de pedra dins l'osberg redreçant-se, agafat al timó tallava el fosc corrent; però l'heroi tranquil, al seu bran acolzant-se, l'estel'nava guaitant a tot indiferent.

Traducció de Xavier Benguerel, 1985

\section{DON JOAN ALS INFERNS}

Quan don Joan baixà cap als avencs ombrosos i un cop lliurà a Caront l'òbol pel pas del riu, un mendicant, de braços venjatius, poderosos, empunyà els rems, a imatge d'Antístenes l'altiu.

Dones de sines fofes, les robes entreobertes, es retorçaven lúbriques sota el cel ennegrit, i, com un gran ramat de víctimes ofertes, al seu quest rossegaven un llarguíssim mugit. 
Rient li requeria Sganarelle les pagues, mentre amb un trèmul dit mostrava don Lluís a tots els morts errívols per les riberes vagues el fill audaç, un dia escarn del seu front gris.

Sota el dol estremida, Elvira, magra i pura, prop del pèrfid espòs un temps amant ardent, semblava reclamar-li el somrís de ventura on brillés la dolcesa del primer jurament.

Un gran home de pedra, rígid dins l'armadura, governant el timó tallava el flux espès:

però el calmós heroi, la mà a l'empunyadura, mirava els solcs de l'aigua sense fer cas de res. 
